\title{
Research on "Creative" Visual Thinking Mode in Visual Communication Design
}

\author{
Siyang Xiao,Yan Liu and Jiayao Wang \\ Jilin Animation Institute, Changchun, Jilin
}

Keyword: Digital technology; Environmental design; Applied research

\begin{abstract}
With the rapid increase of people's living standards the requirements for the surrounding environment also change. Environmental design has a very important influence on people's work and the comfort of life at some level. In the design of aesthetics and enjoyment, the development of digital technology should be fully integrated to enhance its design advantages. This paper, through the elaboration of the concept of digital technology and environmental technology, analyzes the specific application of digital technology in environmental design, and better promotes development of era of environmental design.
\end{abstract}

\section{Introduction}

With the continuous promotion of digital technology, the application of environmental design has attracted wide attention. Due to the good development advantages of digital technology which can better meet the needs of aesthetic development and meanwhile can meet the practical needs of the specific appreciation level and comfort and obviously it has become the main trend of social development to integrate digital technology into environmental design. From the perspective of modern development environment design this paper studies the relationship between digital technology and environmental design in depth. On this basis, the application of digital technology in environmental design is put forward to better promote the development of environmental design and meet the practical needs of people's social life.

\section{Elaboration of Related Concepts}

Environmental Design. Environmental design, which can be understood as the main form of relying on artistic development, influences people's daily activities through specific planning and design of internal or external environment. The main purpose of environmental design is to facilitate people's daily work and life, thus providing a more comfortable and beautiful main space place.

The research scope of environmental design is relatively extensive, and the design stage is a technique performance of the overall environment design. In environmental design, the early stage mainly focuses on traditional drawing design.On this basis the overall design work is completed drawing on discriminating tools and the use of materials. Its techniques are mainly focused on the performance of water powder technique and mark's technique. With the development of digital technology, environmental design has gradually changed, and the design of the early drawings has changed to digital design.

Unlike traditional early drawings design, the overall performance of digital technology design is higher and he perspectivity of the performance graph is more accurate. In the related treatments of materials and colors and so on it appears more real and natural. In the choice of light and shadow, the artistic effect of real expression is also reflected. Digital technology changes traditional design innovatively in a modern way of expression and can enrich traditional design contents and expression form and makes the design presented more realistic and free through the application of a certain virtualized development technology and further perfects the artistic effect in this interactive development experience.

For any art, it cannot survive on its own and needs to rely on other technical support and besides will be affected by other factors, such as economic development, cultural changes and changes in art form. In the development of environmental design, the form of expression of design can be replaced by new and 
higher technology. However, It is worthwhile to note that the expression form of main body of environmental design has developed into a relatively unique expression form after a long development.

Digital Technology. So-called digital technology is used to express and communicate relevant information in relation to processing mainly by using 0 and 1 in the two digital coding form aided with the electronic computer, fiber optic cable and other specific equipment. Digital technology usually include related digital coding, digital compression and digital transmission, etc., which is a vivid embodiment of the informationization of practical development and gradually has become a key part of modern information technology development and is what people often call computer technology and digital technology etc.

For the concept of digital technology, the study is very broad. The object of research is different for the specific content which includes the software and hardware technology of computer development and related information technology viewed from the form of external expression of development such as common network technology or virtual simulation technology etc., The applications of digital technology are very wide, including satellite image analysis technology, network technology and other technologies in the field of high technology, and are different in different fields.

However, in environmental design, the applications of digital technology mainly include the transmission of digital information or related description forming the wonderful development of environmental design. Among the applications computer-aided design is the most prominent part of digital technology, while digital technology is mostly used in the field of engineering design and development. In environmental design, digital technology or related computer aided technology is also involved, because it has the advantages of the development of coexisting of diagram, text or sound and image that traditional information technology does not have.

Relationship between Environmental Design and Dtechnology. With the development of social change, the corresponding design concept also changes, and there is a clear objective requirement for the design and development of technology. The design of high maneuverability and strong control effect has attracted more and more attention,plus the related applications of computer digital technology.

That constantly promote the development and change of the level of beautification and appreciation and the requirements of comfort are more stressed in dedign. This needs the applications of certain digital technology,and strengthen internal storage processing or analysis to deal with the development of the main program, strengthen to realize the designer's main design style, and make it meet the needs of rapid modernization development. On this basis, the overall simplified development of the overall design process is further guaranteed. Changes in this way do not only facilitate the realization of environmental design goals, but promote the development of digital technology.

\section{Specific Applications of Digital Technology in Environmental Design}

Digital Technology Promotes the Development and Updates of Environmental Design Concepts. The application of digital technology in environmental design constantly pushes the designers to update their ideas, because designers have a lot of design ideas at this stage. An opportunity for development is provided by combining with the previous design knowledge base and the application of modern digital technology. Therefore, as designers of environmental design, the use of digital technology should be strengthened, and its application should be reasonable and effective.

Integrating digital technology into environmental design cannot only facilitate the improvement of its own comprehensive design quality but play an important role in promoting for environmental design or the development of digital technology. Costantly integrating new digital development technology into environmental design through the development of the design concept and updates addresses the conflicts between traditional design concept and modern design concept effectively and the contradiction between them is played down. Only in this way can digital technology be used in environmental design better.

For environmental design, it belongs to the interdiscipline of art and science. In order to achieve rapid and normalized development of environmental design, it is necessary to strengthen the related technologies of integration and development. 
The developmental integration of digital technology provides an innovative idea for the continuous development of environmental design not only further enriching the connotation of design of main body but also making the overall design more beautiful and comfortable to achieves the artistic effect of the performance, and increase the sense of art and design in the development.

Digital Technology Accelerates the Pace of Environmental Design. In environmental design, digital technology plays a prominent role in promoting the development. Through the applications of digital technology not only can the normalization and effective processing of the text knowledge be achieved, but also the processing of graphics or related images.can be deepened. From this point of view, it is different from the environment design under the traditional mode of development. For the designers who have just entered the environment design, if they can apply digital technology of modern development well, the overall design can also present the perfect effect.

In the view of comprehensive development, the enhancement of the applications of digital technology in environmental design has effectively promoted the pace of the construction and development of environmental design.

On one hand the main idea of environmental design is to meet the real life needs of target consumers. For the traditional environment design, its modification and improvement are relatively troublesome due to the design method of hand-drawn form. And further applications of digital technology began to gradually replace the traditional hand-painted technology made whole design more accurate and standard not only making norms for the presentation of the artistic effect, but also providing material support for its further development.

Digital Technology Accelerates the Development of Environmental Design. For the developing environmental art design, Only by making full use of the modern digital technology, the image or sound can be presented in aother more visual way, thus achieving the purpose of being realized and conveyed. It not only provides the relative convenience for the overall design development, further but also facilitates the designer's design modification.

The specific applications of digital technology in the environmental design are presented mainly through advanced graphics and other techniques and make technology and art better integrated in the use of instruments and equipment and then make the own development advantages of digital technology appeared. In addition, through the integration of digital technology and traditional technology, the application of digital technology has more tension and appeal. From this point of view, it also promotes the layered development of environmental design. Therefore, in the development of digital technology, the development speed of environmental design has been accelerated, and environmental design has been transformed in the form of multi-efficiency and modernization.

Digital Technology Enhances the Competitive Position of Environmental Design in the Market. Because of the advantages of digital technology and audio and video, it also facilitates the storage of data files, specifically through the application of relevant digital graphics and other software ,and enhance the use of developmental transitions between different digital software. It is not only convenient for users to use, but also can deepen processing and make the overall environmental artistic effect finally presented and perfect the dominant position of environmental design in the fierce market competition.

On one hand, the increasing use of digital technology in the environmental design can reduce the overall design cost and reduce the occurrence of errors in the design and make the improvement of the quality of the overall environmental design. On the other hand, integrating digital technology into environmental design can emphasize the market competitiveness of environmental design works and is not only convenient for the relevant reproduction of the design works, but also the repetitive copy and printing which does not cause damage to the files, but also can keep the culture for a long time, ensuring that the documents can be kept for a long time.

In addition, remote file sharing of resources can be realized through the full use of related network development technology or information transmission technology in digital technology not only improving the efficiency of design development, but also improving the comprehensive quality of environmental design.So in the fierce market competition, environmental design should improve the use of digital technology because it can not only strengthen the main body status of the development of environmental 
design products but also can improve the satisfaction of consumer, to win customers trust and recognition.

Environmental art design affects all aspects of people's life and the use of digital technology should be strengthened in its application of development research. Through the affirmation of various influence value of digital technology in the environmental design the development and updates of the design concept should be further strengthened, the development of environmental design should be accelerated the development speed of environment should be improved and the competitiveness of environment design in the development of the market should be improved, thus the change and development of the environment design can be promoted. So digital technology plays an important role in the development of environmental design. Through the applied research of digital technology in environmental design more emphasis on the development of digital technology has been placed at the theoretical level and convenient advantages have also been provided for the development of environmental design. Therefore in environment design, while the reinforcement of developing the applications of digital technology makes environmental design achieve the most optimal development it also plays a key role in promoting the further improvement of economic and social benefits.

\section{References}

[1] X.C.Li,2014, Research on the application of virtual reality technology in environmental art design. Art Education Research (17):68-71.

[2] J.L.zhong,2015, Application status and development analysis of digital virtual technology in environmental art design. Beauty and the times (City Edition) 01) :76-77.

[3] M.Q.Chen, 2012, The application and development of digital technology in environmental art design. Anhui Polytechnic University Press.

[4] H.W.Ma, 2014, Research on the application of new media art in environmental art design. Beauty and age (middle) (10):85-86.

[5] P.Wang and W.F.Chen 2013, Ecological concept in environmental art design. Research on Design Art (05):51-54.

[6] J.Gan,2013, The application of digital technology in environmental art design. Modern decoration (Theory) (10):115-117.

[7] B.Z.He,2012, Research on the application of virtual reality technology in environmental art design. The popular literature and arts 07:95-96.

[8] H.Wu,2005, Environmental Art Design. Hunan Fine Arts Publishing House.

[9] J.C.Li et al ,2010, Introduction to digital architectural design. China Construction Industry Press.

[10] T. Kuhn ,2013, The Structure of Scientific Revolutions. Peking University Press. 